\title{
Correção de ERros Gramaticais ORAIS NA SAla DE AUlA DE INGLÊS-LE: UM ESTUdO DA Prática e das Crenças de Uma Professora
}

Corrective feedback to oral grammatical mistakes in the English a foreign language classroom: a study of a teacher's beliefs and practices

\author{
Marcia Regina Pawlas Carazzai* \\ Francieli Santin*
}

\section{INTRODUÇão}

De acordo com Figueiredo (2002, p. 45), "identificar e classificar um erro não é uma tarefa fácil, pois sua própria concepção é um tanto complexa, dependendo da teoria linguística usada para abordá-lo". Até a década de 60 , os estudos da linguagem eram baseados principalmente na teoria behaviorista, teoria esta que considerava o erro como hábito malformado, que apresentava um caráter negativo. No início da década de 60, Chomsky (apud FIGUEIREDO, 2002, p. 45) surge defendendo a teoria de que "a língua é adquirida através da internalização de regras, e não a partir da formação de hábitos", onde os erros eram produzidos "devido à formação de hipóteses sobre a segunda língua", apresentando assim um aspecto positivo. Embora a teoria de Chomsky (apud FIGUEIREDO, 2002, p. 45) seja antiga, ele foi pioneiro quanto a considerar o erro como parte do processo de aprendizagem, caracterizando-o como algo positivo.

Em sala de aula, quando da ocorrência de um erro por parte do aluno, é comum haver a correção desse erro, tanto por parte do professor, quanto pelo próprio aluno. Entende-se por correção a atitude tomada no momento em que o erro é concebido. Embora tal atitude possa ser tomada 
pelos colegas ou pelo próprio aluno que comete o erro, muitas vezes é o professor quem toma a atitude de corrigir o erro. Conforme apontado por Cardoso-Brito (2004), seria importante que o professor, ao efetuar essa correção, tivesse em mente quais são seus verdadeiros motivos. Para Cardoso-Brito (2004), é papel do professor oferecer aos seus alunos uma correção consciente e bem planejada.

Ao tomar atitudes para a correção, o professor o faz sob influência de crenças, que podem ser definidas como "opiniões e idéias que alunos (e professores) têm a respeito dos processos de ensino e aprendizagem de línguas" (BARCELOS, 2001, p. 74).

Considerando-se o exposto, apresentamos os resultados de um estudo, de natureza etnográfica, que teve o objetivo de analisar a atitude de uma professora em uma sala de aula de inglês - LE, diante da produção de sentenças gramaticalmente incoerentes produzidas pelos seus alunos. A primeira parte deste artigo consiste da apresentação e classificação das atitudes tomadas por esta professora no momento da produção de erros. Posteriormente, o artigo provê uma investigação das prováveis crenças que a professora tem a respeito de sua prática em relação à correção de erros.

\section{Estudos Sobre A CoRreção de ERros}

A teoria que sustenta esta pesquisa é fruto de um estudo realizado por Lyster e Ranta (1997) em Montreal, com quatro classes de imersão em francês no nível primário, onde cerca de 18 horas de interação em sala foram transcritas. Entre outros resultados obtidos, neste estudo Lyster e Ranta (1997) distinguiram seis categorias de correção, que são:

\section{CORREÇÃo EXPLÍ́CITA}

A modalidade correção explícita se refere ao fornecimento explícito da forma correta, ou seja, após o aluno produzir uma sentença incorreta o professor imediatamente reproduz a mesma frase já corrigida. O professor pode tanto fornecer a resposta correta como deixar claro que o que o aluno disse está errado, mas isso deve acontecer imediatamente após a ocorrência do erro.

\section{REFORMULAÇÃO}

A categoria de reformulação envolve a reprodução modificada de 
toda ou de parte da sentença pelo professor, exceto o erro cometido por seu aluno. É uma repetição da frase equivocada já corrigida, uma repetição com mudança e ênfase. A reformulação é geralmente implícita, a não ser quando o professor usa frases como: "você quis dizer", "use esta palavra" ou "você poderia dizer". No entanto, algumas reformulações podem ser mais salientes, ou seja, frases reformuladas com mais ênfase, pois a reformulação pode enfocar apenas uma palavra ou pode incorporar uma correção de estrutura gramatical. Como a reformulação é apenas uma repetição da frase do aluno corrigida, muitas vezes o aluno pode não perceber que um erro foi cometido e corrigido.

\section{Questões DE CLARIFICAÇÃo}

Questões de clarificação ocorrem quando o aluno produz uma sentença que pode ser mal entendida pelo professor, ou que não está bem formulada de alguma maneira, onde a repetição ou a reformulação da mesma seja necessária. Este tipo de correção pode referir-se tanto a problemas de compreensão quanto a problemas gramaticais, ou a ambos. A questão de clarificação é uma pergunta feita pelo professor permitindo assim que o aluno perceba seu erro e consiga fazer a auto-correção. Entretanto, a questão de clarificação pode incluir a repetição do erro como: "o que você quer dizer com (erro produzido)?

\section{SINAIS METALINGUÍSTICOS}

A correção através de sinais metalinguísticos contém informações, comentários ou perguntas relacionadas às sentenças incorretas produzidas pelo aluno, sem fornecer uma correção explícita da forma correta. Os comentários metalinguísticos geralmente indicam que existe um erro em alguma parte da sentença, fornecendo metalinguagem gramatical que se refere à natureza do erro.

\section{ELICITAÇÃo}

A elicitação engloba três técnicas utilizadas pelos professores. Primeira: o professor estimula o aluno a complementar a frase produzida pelo mesmo, pausando estrategicamente, fazendo com que o aluno reflita sobre sua produção. Segunda: o professor usa perguntas abertas para que o aluno consiga perceber onde está seu erro. Terceira: o professor pode 
pedir aos seus alunos que reformulem as sentenças. É através da elicitação que os alunos podem tentar entender onde está o erro ou o que deve ser corrigido.

\section{REPETIÇÃO}

A categoria repetição refere-se à repetição do professor, em isolado, da sentença em que o aluno cometeu um erro, sendo que esta repetição será geralmente uma pergunta. Na maioria dos casos, os professores ajustam a entonação para enfatizar o erro, fazendo com que o aluno tenha certeza de onde exatamente o erro se encontra.

\section{Estudos SOBRE CRENÇAS}

Crenças têm sido descritas com um conceito complexo (PAJARES, 1992) e difícil de investigar (BARCELOS, 2004). Parte desta complexidade é devido à utilização de diferentes termos para se referir às crenças. Termos como cultura de aprender línguas (BARCELOS, 2000), sistemas pedagógicos (BORG, 1998), e crenças, pressuposições e conhecimentos (BAK: beliefs, assumptions and knowledge) (WOODS, 1996), dentre outros, já foram utilizados em referência às crenças.

Embora não exista uma definição única e uniforme para as crenças, de um modo geral parece haver um consenso que as crenças se referem à natureza da linguagem e ao ensino/aprendizagem de línguas, e ainda que as crenças possam ajudar a interpretação de experiências. De acordo com Barcelos (2001, p. 132), "as crenças sobre aprendizagem de línguas, são crenças a respeito do que é linguagem, do que é aprendizagem de línguas e sobre aspectos pertinentes à linguagem e à aprendizagem, ou toda tarefa de aprender".

O estudo de crenças nesta pesquisa segue a abordagem contextual apresentada por Barcelos (2001), que visa combinar diferentes métodos para a interpretação de crenças, tais como questionários, entrevistas, observação de sala de aula, entre outros, buscando entender um contexto específico, ou seja, considera não apenas a prática da professora em sala de aula, mas também o que ela acredita em relação à sua prática.

Como as crenças são fortes indicadores de como as pessoas agem, podendo até mesmo influenciar as atitudes do indivíduo (BARCELOS, 2001), 
neste artigo são apresentados os resultados de um estudo etnográfico sobre as crenças de uma professora e a sua prática a respeito da correção gramatical oral em sua sala de aula.

\section{METODOLOGIA}

A professora observada nesta pesquisa, chamada aqui de forma fictícia de Marina, leciona inglês há mais de oito anos e formou-se em Magistério. O grupo observado é formado por dez alunos, com idades entre 14 e 17 anos, os quais utilizam o material da Macmillan, denominado Skyline 3b (BREWSTER et al., 2001), o que de acordo com o instituto escolhido para observação das aulas corresponde ao nível High Intermediate 2. Os dados obtidos nesta pesquisa foram coletados em um instituto de línguas no Paraná, no segundo semestre de 2005, no qual Marina se formou e atualmente leciona inglês como Língua Estrangeira.

A coleta de dados, autorizada tanto pela professora como pelos alunos, ocorreu através de observações e gravações em fitas cassetes das aulas da professora, notas de campo e também através de um questionário e de uma entrevista, sendo que nem a professora, nem os alunos sabiam da intenção desta pesquisa durante as gravações das aulas.

Uma vez que o presente estudo trata-se de uma pesquisa etnográfica, que tenta compreender comportamentos e relações das pessoas dentro de um grupo de pessoas em um contexto social específico, seu propósito é descrever e interpretar a cultura e o comportamento das pessoas deste grupo. Como acontece nesta pesquisa, o observador serve como um instrumento de pesquisa, que durante a observação, torna-se um observador participante que além de tomar notas relevantes sobre o que acontece no contexto observado, também questiona os acontecimentos, visando compreendê-los (SPRADLEY, 1979, p. 1980).

Após a observação e a gravação em fitas cassetes, cerca de 13 horas de aula, e as notas de campo tomadas pela pesquisadora durante as aulas, os episódios nos quais os erros gramaticais orais ocorreram e haviam sido corrigidos pela professora, foram transcritos seguindo o modelo de transcrição proposto por Hatch (1992). Posteriormente à transcrição destes episódios, a prática utilizada pela professora para corrigir os alunos foi classificada de acordo com as seis categorias de correção propostas por Lyster e Ranta (1997) comentadas na seção anterior.

Com o intuito de comparar as crenças sobre erros e correção de erros em sala de aula de inglês - LE que a professora defendia, com a prática desenvolvida pela mesma em sala de aula, foi entregue a ela, logo 
após o término das gravações, um questionário com treze questões abertas em português sobre os conceitos, o papel, a necessidade e os significados de correção de erros em sala de aula, a prática de correção e a formação profissional da professora.

No primeiro semestre de 2006, após o início da análise de dados e da transcrição do material já coletado através da observação em sala de aula, uma entrevista em português foi realizada com Marina com a intenção de não apenas obter informações complementares, como também de esclarecer algumas de suas reflexões propostas no questionário e discutir outros pontos importantes da sua prática.

Os dados coletados, tanto através da entrevista, como através do questionário, foram analisados de maneira qualitativa, isto é, significados foram interpretados através do material coletado para a pesquisa, considerando aspectos particulares de um fenômeno, opiniões e motivações. Esta análise vai de encontro com o modelo de análise etnográfico proposto por Spradley $(1979 ; 1980)$, que sugere três tipos de análise; primeira: a análise de domínio, que consiste em identificar as relações existentes em termos, criando categorias ou domínios encontrando assim partes de uma cultura; segunda: a análise taxonômica, que mostra a relação entre os termos identificados na análise de domínio; terceira: a análise temática, onde se analisam os princípios que são recorrentes em um número de domínios e que servem como um relacionamento entre os subsistemas de significado cultural, esta análise visa encontrar a relação existente entre as partes de uma cultura e da cultura como um todo.

\section{ANÁLISE DE DADOS}

Esta seção apresenta a análise de dados baseada nas formas de correção propostas por Lyster e Ranta (1997) em conjunto com as crenças apresentadas por Marina no questionário e na entrevista por ela concedida sobre a correção de erros gramaticais orais e sua prática. Sendo que, das seis categorias expostas pelos autores, apenas uma não foi encontrada nas aulas de Marina. Cada uma das categorias está ilustrada com um exemplo retirado das aulas transcritas. ${ }^{1}$

\section{REFORMULAÇÃO}


Como a reformulação é apenas uma transformação ou mudança da frase do aluno, na maioria das vezes, esta forma de correção pode não ser percebida pelo aluno. Embora esta não tenha sido uma prática frequente de Marina, o exemplo a seguir parece refletir o estudo de Lyster (1998) que caracterizou a reformulação como uma das categorias de correção menos efetiva no sentido de percepção dos alunos.

Neste episódio a professora está fazendo um exercício de pré-leitura com os alunos, que conversam sobre as diferenças culturais existentes entre alguns países. Esta transcrição exemplifica a reformulação e mostra que o aluno não teve reação alguma (linha 4), não repetiu a reformulação, talvez nem tenha entendido isto como uma correção, ou ainda não tenha percebido que um erro gramatical foi cometido durante a sua produção oral.

1. P: what are the differences between Scotland and USA? ah, do you think that there are differences between countries? among countries?

+ ok! concern to what? $?^{2}$

2. Isaa: the + the contrary drivers +

3. P: the way of driving + the way of driving + ok! + how do + ah + how do + Scotland habitants drive?

4. Ton: in the right ++

5. $P$ : side, in the right side + ok? + in the right side

Como pudemos observar, a reformulação por parte da professora ocorre, mas isto pode desencorajar o aluno a tentar perceber o seu erro ou repetir a sentença corretamente. Talvez Marina corrija-o através desta prática de reformulação para não atrapalhar a fluência do aluno, ou não frustrá-lo, já que se trata de um episódio onde os alunos estão expressando suas opiniões oralmente.

\section{CORREÇÃo EXPLÍCITA}

Conforme já mencionamos, a correção explícita é aquela na qual o professor mostra aos alunos diretamente, e logo após o erro ter sido cometido,

\footnotetext{
Os nomes dos alunos participantes desta pesquisa foram abreviados com as primeiras letras de seus nomes para que suas identidades fossem preservadas. Nesta pesquisa ' $P$ ' refere-se à professora enquanto ' $Q$ ' refere-se às questões do questionário. Assim, 'Q10' indica 'Questão10'. 'QE' indica questão da entrevista, logo: QE5 refere-se à questão 5 da entrevista. 'A' significa aula e 'E' episódio, sendo assim: A1E4 significa aula 1 episódio 4 das transcrições da sala de aula.
} 
a maneira apropriada de se produzir a sentença, mostrando claramente ao aluno que sua frase está equivocada.

O episódio a seguir mostra claramente uma correção explícita. É um momento onde a professora continua conversando com seus alunos sobre as diferenças culturais dos países, após os alunos conversarem em pequenos grupos eles estão expondo suas ideias aos outros colegas. Esta prática foi utilizada diversas vezes por Marina durante a observação.

1. Isa: the people are very friendly. the food are?

2. P: the food is

3. Isa: eh... (xxxxx) in Brazil

4. P: and you? + what are you talking about?

5. Mi: Brazil and Japan

6. P: Brazil and Japan, great + it's too different $+\mathrm{ok}+\mathrm{Bia}++$ Japanese +

7. Bea: Japanese food are more vegetarian

8. $\mathrm{P}$ : is more + is vegetarian + is vegetarian

Conforme pudemos perceber, o erro corrigido explicitamente na linha 2 se repete na linha 7 , o mesmo erro gramatical foi produzido por alunas diferentes. Talvez a prática de correção explícita seja uma prática que não chame muita atenção de quem não está sendo corrigido. Diferentemente do que acontecia no estudo realizado por Rauber e Gil (2004), onde a professora observada mostrava-se preocupada com a compreensão do aluno ao ser corrigido explicitamente, nas aulas de Marina, a correção de erros gramaticais nem sempre ocorria seguido de uma explicação sobre a razão da frase ter sido considerada errada.

A respeito deste episódio, Marina comenta que: “... [eu] tentei aí corrigir de uma vez e não cortar a seqüência de trabalho" (QE26). A professora observada parece acreditar que esta é uma correção que leva menos tempo para ser efetuada, e garante que: "[se] você pára e explica, daí o pair work que eles fizeram para o grupo já corta" (QE26). Marina parece preferir esta forma de correção durante os exercícios de produção oral de seus alunos.

\section{REPETIÇÃO}

Uma outra estratégia de correção utilizada pela professora Marina foi a prática da repetição, que consiste em repetir a frase incoerente ou incorreta produzida pelo aluno, utilizando-se da entonação para enfatizar o erro cometido.

No episódio seguinte a professora está corrigindo exercícios que envolvem o passado particípio dos verbos, quando um aluno comete um 
erro no passado particípio do verbo esquecer em inglês, como a professora pronuncia o erro de maneira diferente, a aluna logo percebe o erro que está cometendo e concorda produzindo um som de afirmação e entendimento: “ah" (linha 4).

1. P: letter $b(x x x x x)$

2. Isa: $(\mathrm{xxxxx}) \mathrm{I}+\mathrm{I}$ 've forgotton $(\mathrm{xxxx})$

3. P: I've forgotton? + isn't it letter a? + It's forget + forgot + FORGOTTEN + not FORGOTTON

4. Isa: ah, isn't forgotton... + no, no

5. P: ah + I think she's wrong + forgotten

6. And: tá certo, eu aprendi isso... (alunos riem)

7. P: you learned forgotton? + it's wrong + here is forgotten

A professora observada raramente fez da repetição uma estratégia para induzir o aluno a perceber seu erro. Os exemplos encontrados nos dados coletados mostram que quando a correção ocorreu através da repetição, Marina forneceu sempre a forma correta, não oferecendo ao seu aluno a oportunidade de refletir sobre o erro cometido.

\section{ELICITAÇÃo}

A elicitação é a prática que consiste em dar um tempo ao aluno para que ele reflita sobre a frase produzida incorretamente com o objetivo de que o mesmo perceba o seu erro e corrija-o. O episódio que melhor exemplifica esta prática está transcrito em seguida. Este é um episódio no qual os alunos estão conversando sobre os hábitos alimentares e saudáveis de cada um.

1. Bea: I eat alone.

2. P: Bia, do you eat alone? why?

3. Bea: yes teacher + I eat alone + because my grandfather eat before me.

4. P: ah + your grandfather...

5. Bea: eat before me

6. P: eat? +

7. Bea: no + no + eats before me

8. $\mathrm{P}: \mathrm{ok}+$ remember + third person in the singular + he she it + use $\mathrm{s}+$ remember?

9. Bea: ok + my grandfather eats né?

10. P: great Bia, it's ok 
Após o uso da técnica de correção através da elicitação, onde a professora sugere a aluna através de uma pergunta (linha 4 e 6) que a aluna repense na frase produzida, a professora utiliza-se de uma outra técnica de correção chamada de sinais metalinguísticos (discutido na sequência). De acordo com Marina, a técnica de elicitação proporciona ao aluno a chance de repensar sua produção oral e permite a auto-correção por parte do próprio aluno: "quando eles deduzem por si mesmos, eles aprendem melhor" (QE20).

De acordo com Lyster (1998), a correção através da elicitação deveria ser utilizada com mais frequência, pois proporciona ao aluno a chance de perceber seu erro e realizar a auto- correção, tornando a correção mais eficaz. Mesmo Marina mostrando-se consciente de que esta é uma maneira de se corrigir efetivamente seus alunos, ela pouco praticou esta forma de correção durante as aulas observadas.

\section{SinAis METALinguísticos}

A correção através dos sinais metalinguísticos envolve uma explicação sobre os aspectos gramaticais da língua em questão. Esta foi uma das técnicas mais utilizadas por Marina, que de acordo com os dados coletados, parece trabalhar com essas correções porque sugere acreditar que "a língua não pode ser meramente falada. A comunicação precisa ser feita de forma mais correta e eficaz possível" (Q12, ênfase da resposta ao questionário), e ainda que "a correção gramatical ajuda o aluno a falar corretamente, com um bom nível de comunicação" (Q13). Com isso, podemos perceber uma contradição nas crenças de Marina: ao mesmo tempo em que ela se mostra preocupada com a fluência de seus alunos, quando corrige de maneira explícita, ela também parece acreditar que a produção oral deve-se mostrar "bem feita em uma língua"(QE3), enfatizando que o aluno "precisa atingir um bom nível de produção em termos de concordância gramatical, concordância verbal..." (QE3). Sendo assim, Marina preocupa-se tanto com a fluência quanto com a forma produzida por seus alunos.

Marina, em sua entrevista, sugere que a correção através de sinais metalinguísticos (ela não se refere a este termo e sim a uma "parte mais técnica") "é uma ótima forma deles [os alunos] se conscientizarem do erro" (QE7), ela parece acreditar que esta forma de correção é "válida, mas não como regra geral, como $80 \%$ do tipo de correção. É chato" (QE9), pois de acordo com Marina, "Você tem que ensinar, não chegar a discorrer uma tese sobre isso [o erro]" (QE10).

No episódio selecionado para exemplificar esta prática, os alunos estão corrigindo em conjunto com a professora a tarefa do livro de tarefas. 
No exercício em questão os alunos deveriam escrever sentenças utilizando a estrutura have / get something done. Os alunos estão tendo dificuldade com o passado particípio dos verbos.

1. Lui: you had your hair cut + é + cutted

2. P: não + cut

3. S1: cut cut cut

4. Lui: in the + at the hairdresser

5. P: muito bem + Isaa

6. Isaa: I have my chest checked at the hospital

7. P: veja Lui + Lui e todo mundo + vocês tem que saber a terceira coluna desses verbos pra fazer esse exercício na prova + não é cutted + é cut + senão vocês não vão acerta na prova gente + ok?

8. P: make sentences + I'm going to have my hair cut next week $+\mathrm{Mi}+$ number one

9. Mi: hum ++

10. P: é todo o sábado então tem que ser presente simples tá

11. Mi: she get

12. P: [she gets

13. Mi: é ++

14. P: she gets her car +

15. Isa: she GETS?

16. P: aham + GETS ++ agora o verbo na terceira coluninha + washed + she gets her car washed every Saturday + se é todo sábado + é uma coisa que ela faz sempre + presente simples + ok ++ number two Bia

Podemos constatar os sinais metalinguísticos quando Marina chama a atenção de seus alunos para a utilização do tempo verbal correto, lembrando seus alunos do que eles dever saber para utilizar a estrutura gramatical corretamente (linha 7), onde a professora previne um erro gramatical sugerindo o tempo verbal (linha 10) e também onde a estrutura gramatical que deve ser utilizada para resolver o exercício proposto é retomada (linha 16).

Durante a análise dos episódios percebemos que quando Marina corrigia através dos sinais metalinguísticos, ela fornecia uma explicação na língua mãe (português), às vezes com as terminologias na língua alvo (inglês) (A1E4; A2E3; A3E1; dentre outros). Com relação ao uso da língua mãe para as correções através de sinais metalinguísticos, Marina parece acreditar que "eles [os alunos] não conseguem acompanhar o raciocínio" (QE15) e que "explicação de regras gramaticais dadas em inglês tem que ser em nível avançado" (QE16). Quanto à terminologia utilizada algumas vezes na língua alvo (A1E4; A13E3), Marina parece acreditar ser importante o uso 
na língua alvo por encontrar esta terminologia nos livros e para que os alunos associem esta terminologia, pois no livro "a terminologia" vai ser em inglês (QE17).

\section{Questões DE CLARIFICAÇÃo}

A única forma de correção de erro que não consta na prática observada de Marina foi a questão de clarificação, ou seja, ela não pediu em momento algum, das observações em sala de aula, para que seus alunos repetissem suas falas erradas, não tentou, através desta categoria fazer com que os alunos percebessem seus erros e se auto corrigissem.

\section{AS CRENÇAS}

Na seção anterior, alguns episódios, nos quais a professora oferecia correção gramatical oral aos erros gramaticais de seus alunos, foram transcritos e classificados de acordo com as categorias propostas por Lyster e Ranta (1997), juntamente com as crenças que Marina apresentou em seu questionário e entrevista. A próxima seção apresenta as crenças que a professora observada parece ter sobre correção e erro, a influência de antigos professores, a linguagem utilizada por ela durante as correções e as formas que podemos corrigir, enfim, reflexões sobre a sua prática em sala de aula. Os dados que servem de base para esta seção foram coletados através do questionário e da entrevista.

\section{Crenças Sobre Correção E Erro}

De maneira geral, Marina sugere através dos dados analisados que "o erro deve ser encarado como algo positivo" (Q4), que "faz parte do processo de aprendizagem" (QE5) e que "com os alunos também se aprende bastante" (Q2). Ela parece acreditar que o aluno "procura tirar um bom proveito do ato de correção" (Q4), sendo que, "corrigir um aluno não pode tomar proporções exageradas" (Q3).

Estas crenças apresentadas por Marina a respeito de correção e erro vão de encontro com os conceitos apresentados por Chomsky (apud FIGUEIREDO, 2002), onde os erros são considerados positivos, uma vez que a maioria deles é resultado da tentativa dos indivíduos usarem o que já aprenderam para aprender ainda mais, ou seja, formularem hipóteses sobre 
a língua. A palavra erro, sob a perspectiva tanto de Chomsky quanto de Marina, passa a ser associada à aprendizagem.

\section{Crenças Sobre a Influência de Antigos Professores}

Os dados sugerem que Marina encara a sua aprendizagem de língua estrangeira como algo "prazeroso, pois sempre gostei de estudá-la [a língua inglesa]" (Q2). Marina ainda sugere que queria ser corrigida pelo seu professor e que "nunca me constrangi com isso [ser corrigida]" (Q2), quando relembra que "sempre pedi [a] ao professor que me corrigisse caso eu cometesse erros" (Q2). Marina parece acreditar que é influenciada pelas suas próprias experiências: “... eu acho de repente que a gente tira muita base pela gente. Eu tenho certas coisas que quando eu vejo, a voz do professor que me ensinou vem na minha consciência" (QE19). Como Marina parece ter tido uma experiência positiva durante sua própria aprendizagem, ela busca em sua prática ensinar os alunos a aceitar a correção como algo positivo, sendo mais uma vez o reflexo das ideias defendidas por Chomsky (apud FIGUEIREDO, 2002).

\section{Crenças sobre a Linguagem Utilizada Durante a Correção}

Marina parece estar preocupada com a linguagem utilizada para corrigir seus alunos, e em alguns episódios (A7E1) ela usa a frase "fica melhor assim" para corrigir seus alunos, e os dados sugerem que Marina parece acreditar que esta é "uma maneira polida de dizer você errou"(QE23), querendo dizer que "você errou não é coisa do outro mundo. Sinta-se confortável em fazer isso, mas vamos fazer melhor" (QE23). Assim, poderia ser dito que Marina parece preocupar-se em não frustrar ou inibir o aluno com a correção.

\section{CRENÇAS SOBRE OS TIPOS DE CORREÇÃO}

Marina parece acreditar na variação de maneiras de corrigir, sugerindo que "toda forma é válida" e que "... não existe a melhor maneira, a mais certa, todas são boas..." (QE28).

Marina demonstra estar consciente da forma de correção explícita quando sugere que uma das maneiras que podem ser usadas para corrigir 
os alunos "é corrigindo já dando pronto: the food are... no, no... the food is." Outra maneira sugerida por Marina é a de elicitação: "Fazer com que eles descubram o que está errado, isso é muito bom, eu acho que é até melhor do que dar pronto" (QE6).

Após comentar com Marina, durante a entrevista, sobre as seis categorias de correção propostas por Lyster e Ranta (1997), ela pareceu se mostrar mais interessada pela categoria de repetição: “... essa da entonação eu acho que funciona" (QE19) "eu acho que essa da entonação pega” (QE19), talvez porque para Marina a voz pareça ser algo marcante. Durante a entrevista, Marina comenta sobre uma aluna sua que diz lembrar da voz dela quando chega em casa: "Em casa ela [aluna de Marina] me vê falando that's it" (QE19). Talvez por isso Marina se mostre interessada por esta categoria, por acreditar que sua voz exerce alguma influência sobre seus alunos.

\section{CONSIDERAÇõEs FinAIS}

Neste artigo reportamos os resultados de uma pesquisa etnográfica que investigou a prática de uma professora de inglês - LE ao corrigir os erros gramaticais orais de seus alunos. Além disso, nesta pesquisa, as crenças da professora observada em relação à sua prática de correção de erros foram analisadas.

Através dos dados coletados, pudemos concluir que a professora observada corrigia os erros gramaticais orais de seus alunos com muita frequência, utilizando-se de mais de uma das categorias de correção propostas por Lyster e Ranta (1997). A correção explícita e a correção através de sinais metalinguísticos foram as duas formas de correção que mais ocorreram durante a observação da prática de Marina. Sobre a categoria de correção explícita, Marina sugere em sua entrevista e questionário que prefere correções mais breves, como a correção explícita, para evitar o corte da fluência durante a produção oral dos alunos. A respeito da correção através de sinais metalinguísticos, Marina parece acreditar que desta maneira os alunos podem se conscientizar de que cometeram um erro, e assim preocuparse com a forma produzida no momento da comunicação.

Apenas uma das categorias de correção apresentadas por Lyster e Ranta (1997) não foi encontrada na prática observada, a questão de clarificação. Como a professora observada não conhecia as teorias apresentadas neste artigo, poderíamos sugerir que ela agiu influenciada por suas próprias crenças. Outros estudos com professores que conheciam estas categorias de correção já foram realizados (RAUBER; GIL, 2005; 
CARAZZAI, 2004). O estudo de Rauber e Gil (2005) mostrou que a professora observada, que conhecia a pesquisa de Lyster e Ranta (1997), utilizou-se de todas as categorias de correção em suas aulas, diferentemente de Marina que não conhecia tais categorias e não trabalhou com uma variação mais ampla das formas de correção em sala de aula.

Marina menciona diversas vezes tanto em sua entrevista como em seu questionário que o erro é algo positivo e que faz parte do processo de aprendizagem. Assim, poderia se argumentado que sua prática está relaciona com as definições de Chomsky (apud FIGUEIREDo, 2002, p. 45) onde os erros "são vistos como algo positivo, como um resultado natural no processo de aquisição da língua".

Assim pudemos concluir que além da prática de Marina ser norteada pelos conceitos de Chomsky (apud FIGUEIREDO, 2002) de que o erro faz parte do processo de aprendizagem, a correção de erros gramaticais orais é realizada para que seus alunos possam se comunicar de maneira fluente e precisa, ou seja, ela corrige para que seus alunos não possam apenas se comunicar, mas sim se comunicar com precisão.

Como a professora que este estudo foca não tem conhecimento do estudo realizado por Lyster e Ranta (1997), poderíamos sugerir que outras pesquisas investiguem até que ponto o conhecimento das teorias pode influenciar a prática de uma professora. Além disso, uma vez que este estudo limitou-se a estudar apenas a correção de erros gramaticais orais e as crenças da professora em questão, outros estudos poderiam enfocar nas crenças dos alunos em relação aos erros cometidos e as repostas dos alunos em relação às correções feitas pelo professor.

Gostaríamos de acrescentar que acreditamos que os resultados deste trabalho ajudaram a iluminar nossas práticas pedagógicas bem como nosso conhecimento teórico. Durante a produção deste artigo, refletimos sobre a prática pedagógica e concluímos que se conhecemos as categorias de correção propostas por Lyster e Ranta (1997), isso pode refletir em nossa prática em sala de aula. Logo, os alunos poderão ser corrigidos de várias formas, o professor estará mais consciente no momento da correção, sabendo o motivo pelo qual está corrigindo e os efeitos de cada tipo de correção. Considerando que é papel do professor oferecer uma correção bem planejada e não apenas efetivá-la (CARDOSO-BRITO, 2004), o conhecimento das teorias que suportam esta prática poderia facilitar o trabalho do professor.

Finalmente, este estudo parece ter despertado interesse em Marina acerca das maneiras de como podemos corrigir os erros gramaticais de nossos alunos, ela parece ter refletido sobre a maneira como corrigia seus alunos e as crenças que sustenta em relação à sua prática, mostrando interesse no resultado desta pesquisa. Considerando a reação de Marina, pudemos 
perceber que estudos desta natureza podem contribuir para a reflexão sobre práticas pedagógicas por parte de todos os envolvidos diretamente com a pesquisa.

\title{
AGRAdECIMENTOS
}

Agradecemos à Marina, por sua participação nesta pesquisa, e à professora Raquel C. M. de Carvalho pelas sugestões feitas à primeira versão deste artigo.

\section{RESUMO}

Este artigo reporta os resultados de um estudo etnográfico que investigou a relação entre a correção de erros gramaticais orais em uma sala de aula de inglês como língua estrangeira e as crenças da professora observada sobre esta prática. Os dados coletados incluem observação das aulas da professora por cerca de 13 horas, notas de campo, um questionário aberto e uma entrevista com a professora. Os resultados indicam que a professora corrigia os erros gramaticais orais produzidos por seus alunos e que os tipos de estratégias de correção mais utilizados foram a correção explícita e a correção através de sinais metalinguísticos. A professora demonstrou-se preocupada tanto com a fluência de seus alunos como com a maneira com que estes se comunicavam na língua estrangeira, ocorrendo a correção sempre que estes objetivos não eram atingidos sob o ponto de vista da professora.

Palavras-chave: Correção de Erros; Crenças; Prática.

\begin{abstract}
This paper reports the results of an ethnographic study which investigated the relation between corrective feedback to oral grammatical mistakes in an English as a foreign language classroom and the observed teacher's beliefs about her practices. Data collected includes about 13 hours of classroom observation, field notes, a questionnaire and an interview with the teacher. The results indicate that the teacher corrected her students' oral grammatical mistakes and that the most recurrent types of strategies were explicit correction and metalinguistic signals. The teacher seemed to be concerned both with her students' fluency and accuracy in the foreign language, and feedback
\end{abstract}


was provided at all times that these objectives were not reached from the teacher's point of view.

Keywords: Corrective Feedback; Beliefs; Practice.

\section{REFERÊNCIAS}

BARCELOS. A. M. F. Crenças sobre aprendizagem de línguas, lingüística aplicada e ensino de línguas. Linguagem \& Ensino, v. 7, n.1, p.123-156, 2004.

Metodologia de pesquisa de crenças sobre aprendizagem de línguas: Estado da Arte. Revista Brasileira de Lingüística Aplicada, v.1, n.1, p.71-92, 2001.

. Understanding teachers' and students' language learning beliefs in experience: A Deweyan Approach. Tese (Doutorado em teaching English as a second language) - The University of Alabama, Tucaloosa, USA, 2000.

BORG, S. Teachers' pedagogical systems and grammar teaching: a qualitative study. TESOL Quarterly, 32/1, p. 9-38, 1998.

BREWSTER, S.; DAVIES, P.; ROGERS, M. et al. Skyline 3b. Oxford, UK: Macmillan, 2001.

CARAZZAI, M. R. P. Correção de erros na sala de aula de inglês como língua estrangeira: considerações preliminares de um estudo etnográfico. In: SOUZA; BRANCO; LOPES (Org.). Universidade: Ação e interação. 1 ed. Guarapuava: Editora Universitária da UNICENTRO, 2004 , v. 2 , p. $212-217$.

CARDOSO-BRITO, S. A. Correção e tratamento de erros e seus possíveis efeitos na produção oral no processo de aprendizagem/aquisição de língua estrangeira em classes de adolescentes. In: CONSOLO, D. A.; VIEIRA-ABRAHÃO M. H. (Org.). Pesquisas em lingüística aplicada: ensino e aprendizagem de língua estrangeira. São Paulo: Editora Unesp, 2004, p.131-153.

FIGUEIREDO, F. J. Q. Aprendendo com os erros: uma perspective comunicativa de ensino de línguas. Goiânia: editora da UFMG, 2002.

HATCH, E. Discourse and language education. London: Cambridge University Press, 1992.

LYSTER, R. Negotiation of form, recasts, and explicit correction in relation to error types and learner repair in immersion classrooms. Language Learning, v.48, n.2, p. 183-218, 1998.

LYSTER, R.; RANTA L. Corrective feedback and learner uptake: negotiation of form in communicative classrooms. Studies in second language acquisition, v. 19, p. 37-66, 1997.

PAJARES, F. M. Teacher's beliefs and educational research: cleaning up a messy construct. Review of Educational Research, v.62, n.3, p. 307-332, 1992.

RAUBER, A. S.; GIL, G. Correção de erros gramaticais de inglês - LE em ambiente comunicativo. In: GIL, G.; RAUBER, A. S. CARAZZAI, M. R. P.; BERGSLEITHNER, J. M. (Org.). Pesquisas qualitativas no ensino e aprendizagem de lingua estrangeira: a sala de aula e o professor de LE. Florianópolis: Palotti, 2005. p. 149-166.

. Feedback to grammar mistakes in EFL classes: A case study. Revista Brasileira de 
CARAZZAi, M. Correção de Erros Gramaticais Orais na Sala de Aula de Inglês-Le...

Linguística Aplicada, UFMG, v. 4, n. 1, p. 277-289, 2004.

SPRADLEY, J. P. Participant observation. Orlando: Harcourt Brace Jovanovich College Publishers, 1980.

1979.

. The ethnographic interview. Orlando: Harcourt Brace Jovanovich College Publishers,

WOODS, D. Teacher cognition in language teaching: Beliefs, decision-making, and classroom practice. Cambridge: Cambridge University Press, 1996.

Submetido em: 12/05/2007.

Aceito em: 31/03/2009. 